\title{
The Molecular Mechanism Underlying Continuous Exercise Training-Induced Adaptive Changes of Lipolysis in White Adipose Cells
}

\author{
Junetsu Ogasawara, ${ }^{1}$ Tetsuya Izawa, ${ }^{2}$ Tomonobu Sakurai, ${ }^{3}$ Takuya Sakurai, ${ }^{1}$ Ken Shirato, \\ Yoshinaga Ishibashi, ${ }^{1}$ Hitoshi Ishida, ${ }^{4}$ Hideki Ohno, ${ }^{1}$ and Takako Kizaki ${ }^{1}$ \\ ${ }^{1}$ Department of Molecular Predictive Medicine and Sport Science, Kyorin University, School of Medicine, Mitaka, Tokyo 181-8611, Japan \\ ${ }^{2}$ Graduate School of Health and Sports Science, Doshisha University, Kyotanabe, Kyoto 610-0394, Japan \\ ${ }^{3}$ Faculty of Culture and Sport Policy, Toin University of Yokohama, Yokohama, Kanagawa 225-8503, Japan \\ ${ }^{4}$ Department of Third Internal Medicine, Kyorin University, School of Medicine, Mitaka, Tokyo 181-8611, Japan \\ Correspondence should be addressed to Junetsu Ogasawara; junetsu@ks.kyorin-u.ac.jp
}

Received 6 February 2015; Revised 4 April 2015; Accepted 27 April 2015

Academic Editor: Eric Doucet

Copyright (C) 2015 Junetsu Ogasawara et al. This is an open access article distributed under the Creative Commons Attribution License, which permits unrestricted use, distribution, and reproduction in any medium, provided the original work is properly cited.

\begin{abstract}
Physical exercise accelerates the mobilization of free fatty acids from white adipocytes to provide fuel for energy. This happens in several tissues and helps to regulate a whole-body state of metabolism. Under these conditions, the hydrolysis of triacylglycerol (TG) that is found in white adipocytes is known to be augmented via the activation of these lipolytic events, which is referred to as the "lipolytic cascade." Indeed, evidence has shown that the lipolytic responses in white adipocytes are upregulated by continuous exercise training (ET) through the adaptive changes in molecules that constitute the lipolytic cascade. During the past few decades, many lipolysis-related molecules have been identified. Of note, the discovery of a new lipase, known as adipose triglyceride lipase, has redefined the existing concepts of the hormone-sensitive lipase-dependent hydrolysis of TG in white adipocytes. This review outlines the alterations in the lipolytic molecules of white adipocytes that result from ET, which includes the molecular regulation of TG lipases through the lipolytic cascade.
\end{abstract}

\section{Introduction}

Obesity, which results from the energy intake that is in excess of energy expenditure, is a major global health problem not only in developed nations (western world) but in lowand middle-income countries (less developed countries) [1]. White adipocytes are capable of storing excess energy as triacylglycerol (TG), and they play a key role in energy metabolism by providing free fatty acids (FFA) and glycerol through the hydrolysis of TG. The induction of lipolysis, as well as the inhibition of TG synthesis in white adipocytes, has been considered a target of therapy for the prevention and improvement of obesity and its related disorders. Therefore, clarifying the mechanisms underlying the physical exerciseinduced alteration of lipolytic molecules in white adipocytes would be useful for establishing a new method for exercise therapy as well as for understanding the biological meanings of the lipolytic events themselves.

This elucidation of lipolysis has demonstrated how ectopic lipid accumulation in skeletal muscle and liver is closely associated with insulin resistance syndrome and diabetes [2]. In particular, the flux of muscular fatty acids is known to play a pivotal role in the development of the abnormalities of muscle and whole-body energy metabolism [3], demonstrating that an increase in the consumption of intramuscular lipids via mitochondrial $\beta$-oxidation would be beneficial for the prevention of obesity-related disorders. Indeed, in previous studies, ET has been shown to increase the metabolic utilization of lipids in both healthy [4] and obese humans [5] and reduce lipid storage in liver [6]. In addition, it appears that ET-induced loss of the absolute content of lipid in white adipocytes per se has a positive 
effect on reducing the levels of the redistribution of lipids in other tissues through an attenuation of synthetic substrate content, that is, FFA and glycerol. Thus, ET would be a highly effective tool for reducing ectopic fat accumulation and/or increasing the hydrolysis of TG in white adipocytes themselves.

The molecular mechanisms underlying lipolysis in white adipocytes are known to be regulated mainly by hierarchical activation of the lipolytic cascade, which is modified through both an $\alpha$ - and $\beta$-AR-cAMP production system, thereby distally exerting a changeover to the hydrolytic action of lipases. The stimulation of these two ARs induces opposite effects: $\alpha$-antilipolytic and $\beta$-lipolytic (details are described in the next section). Of note, it has been shown that complete activation of lipolysis in white adipocytes is only obtained when catecholamines were in the presence of an $\alpha_{2}$-AR antagonist in human, although there are no changes observed in rodents [7]. This $\alpha_{2}$-antilipolytic component counteracting the $\beta$-AR-mediated lipolysis has been well known as the " $\alpha_{2} / \beta$-adrenergic balance" [8]. On the other hand, Arner and colleagues [9] have shown that $\alpha_{2}$-ARs modulate lipolysis at rest, whereas the $\beta$-ARs modulate lipolysis during physical exercise, even if $\alpha_{2} / \beta$-adrenergic balance exists in human white adipocytes. In addition, it has been demonstrated that the number of $\alpha_{2}$-ARs in jerboa, dormouse, and rat is lower than that in humans [10], suggesting that catecholaminesinduced lipolysis in rodents, which have low number of $\alpha_{2}$ ARs, is regulated through alteration in $\beta$-lipolytic function. Therefore, the experiments using the jerboa, dormouse, and rat would be helpful for elucidation of physical exerciseinduced molecular changes in lipolytic molecules in human white adipocytes, because $\beta$-ARs modulate lipolytic response during physical exercise in humans [9]. It has been widely accepted that ET facilitates hormone-stimulated lipolysis in white adipocytes in mammals $[11,12]$. However, the effects of ET on both the molecular behavior and on the expression levels of lipolytic molecules in white adipocytes remain to be missing pieces of the puzzle, although recent evidence has identified both new lipase and lipolytic cofactors: adipose triglyceride lipase (ATGL) [13], PAT family proteins [14], comparative gene identification-58 (CGI-58) [15], and lipotransin [16].

The purpose of this review is to marshal the fact that exercise training (ET) induced changes in the lipolytic molecules via $\beta$-AR, commonly expressed in white adipocytes of human and rodents. The introduced results of this review are mixed with those obtained from human and experimental animals. However, the consideration of this viewpoint appears to enable a deepening of understanding lipolytic events in white fat cells by ET, because ETinduced adaptive changes of lipolytic molecules in white adipocytes are a universal mechanism in mammalian species. Together, first, the currently known mechanism(s) of the lipolytic cascade and the molecular behavior of lipases and cofactors are outlined. Then, attention is focused on the ET-induced adaptive changes of lipolytic molecules, which were mainly obtained from our studies of white adipocytes.

\section{Basic Structure of the Lipolytic Cascade in White Adipocytes}

Lipolysis in white adipocytes is regulated by a multifaceted phenomenon that is subject primarily to distinct temporal controls such as hormonal stimulation via catecholamines. The hormonal activation of lipolysis in adipocytes is mediated via a traditional cAMP-dependent signal transduction process $[17,18]$ (Figure 1(a)). The stimulation of G-protein coupled receptors (GPCRs), that is, $\beta_{1^{-}}, \beta_{2^{-}}$, and $\beta_{3}$-adrenergic receptors ( $\beta$-ARs), induces a conformational change in the $\mathrm{G} \alpha$ subunit of the heterotrimeric $\mathrm{G}$ protein $(\mathrm{G} \alpha \beta \gamma)$ that leads to GDP release and GTP binding. Activated G $\alpha$ s leads to the activation of adenylyl cyclase (AC) and to the production of cAMP. However, the stimulation of GPCRs, that is, $\alpha_{2}$-adrenergic receptor [19], adenosine receptor [20], and prostaglandin E2 receptor [21], which stimulate $\mathrm{G} \alpha \mathrm{i}$, causes the inactivation of $\mathrm{AC}$ and reduces the production of cAMP, resulting in an attenuation of the lipolytic response. In addition, insulin attenuates intracellular cAMP production through increases in phosphodiesterase-3B (PDE-3B) activity, which changes $c A M P$ to AMP via the activation of protein kinase B/AKT (Figure 1(b)). An increased intracellular cAMP level phosphorylates and activates CAMP-dependent protein kinase A (PKA) [22, 23] and subsequently phosphorylates hormone-sensitive lipase (HSL); it is well known that the phosphorylation of HSL at Ser563, Ser659, and Ser660, by cAMP-dependent protein kinase (PKA), enhances its enzymatic activity and that extracellular-regulated kinase (ERK) induces the phosphorylation of HSL at Ser600 in 3T3-L1 adipocytes [24], although there are no studies supporting this result in primary mammalian white adipocytes. Phosphorylated HSL activates the hydrolysis of TG in adipocytes [25] through the translocation of HSL from the cytoplasm to the surface of lipid droplets [26]. On the other hand, an inhibitory effect of insulin has been reported on HSL activity [27, 28], and AMP activated protein kinase (AMPK) attenuates HSL activity through an increase in its phosphorylation at Ser565 [29].

In 2004, three groups independently published the discovery of an enzyme that could hydrolyze TG [13, 30, 31] and named it adipose triglyceride lipase (ATGL). Unlike HSL, ATGL has no specificity for the hydrolysis of MG, cholesterol esters, or retinyl esters. ATGL does, however, have a substrate specificity for TG that is 10 -fold higher than that for DG [3], indicating that it selectively acts as the first step in TG hydrolysis and that its hydrolytic function is not restricted to the catabolism of lipid droplets [32] in adipose tissue. Moreover, two phosphorylation sites of ATGL, at Ser404 and Ser428, have been identified in the C-terminal region in humans $[13,33]$. In contrast with HSL, however, the functional roles of enzyme phosphorylation, as it involves protein kinases, remain unknown. Together, both HSL and ATGL act hierarchically to regulate TG hydrolysis: ATGL initiates lipolysis by removing the first FA from TG to, in turn, produce DG; HSL generates an additional FA from DG and MG to produce glycerol (Figure 2). In these events, the phosphorylation of lipases plays a central role in the 


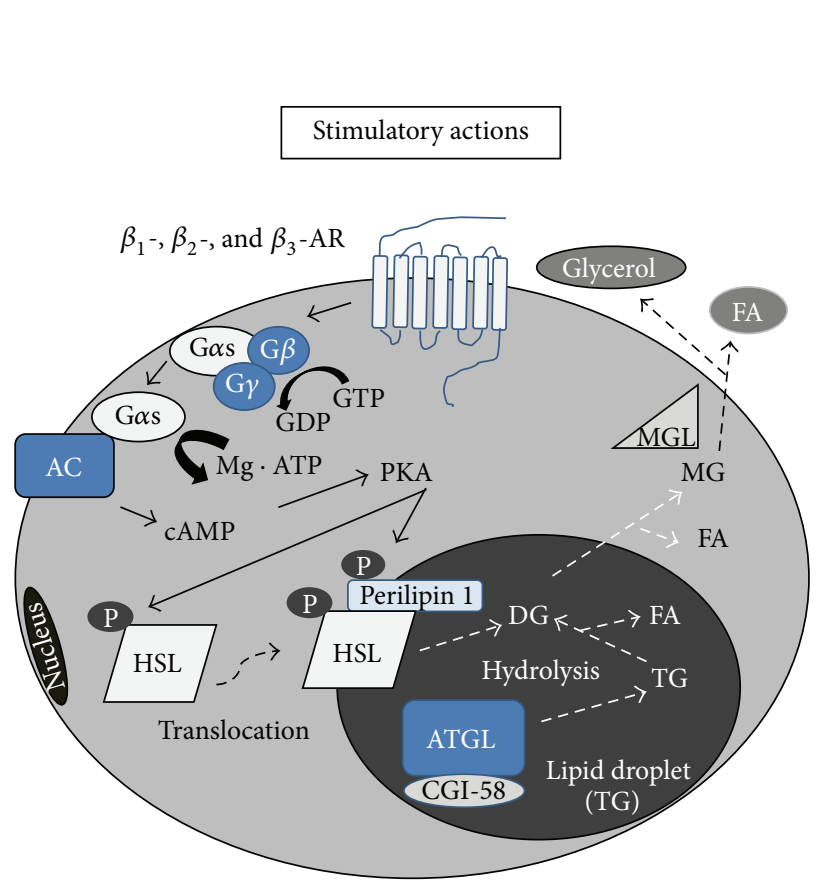

(a)

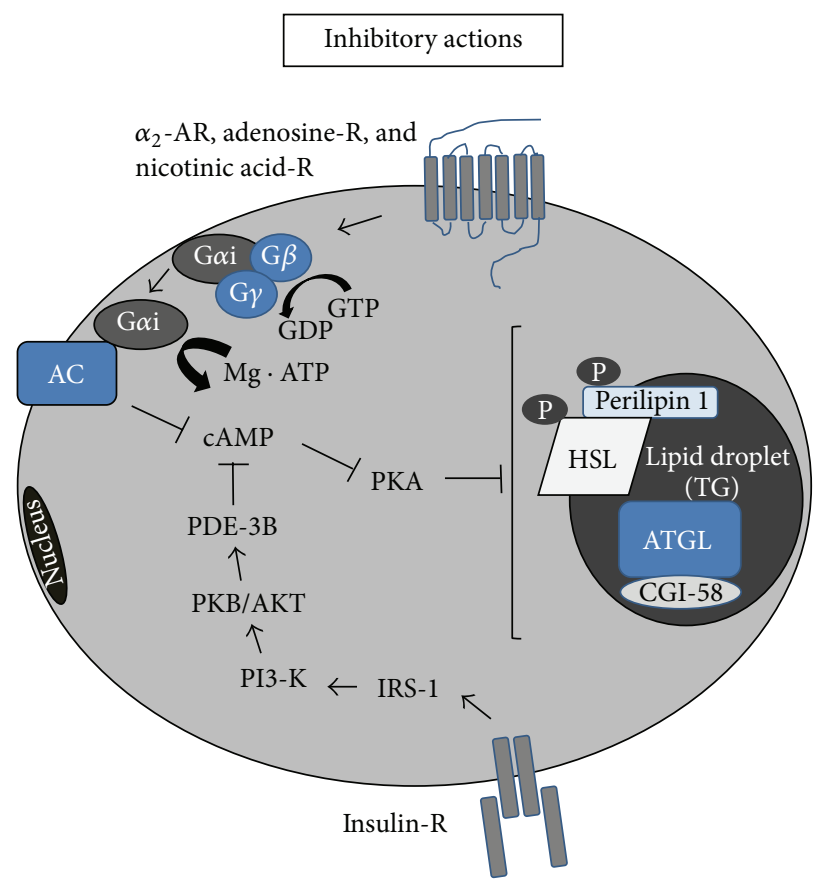

(b)

FIGURE 1: Lipolysis in white adipocytes is mainly regulated through GPCRs that localize on the plasma membrane. (a) Under stimulatory conditions, ligands binding to GPCRs, that is, $\beta_{1^{-}}, \beta_{2^{-}}$, and $\beta_{3}-\mathrm{AR}$, activate AC through the action of G $\alpha$ s, resulting in an increase in PKA activity through the accumulation of intracellular cAMP, and, in turn, PKA phosphorylates and activates HSL. Phosphorylated HSL translocates on the lipid droplet and thereby activates lipolysis. (b) On the other hand, ligands binding to GPCRs, that is, $\alpha_{2}$-AR, adenosine$\mathrm{R}$, and nicotinic acid-R, attenuate lipolysis via a reduction in cAMP production. Insulin receptor signaling also inhibits lipolytic response via the activation of PDH-3B, a cAMP-degrading enzyme.

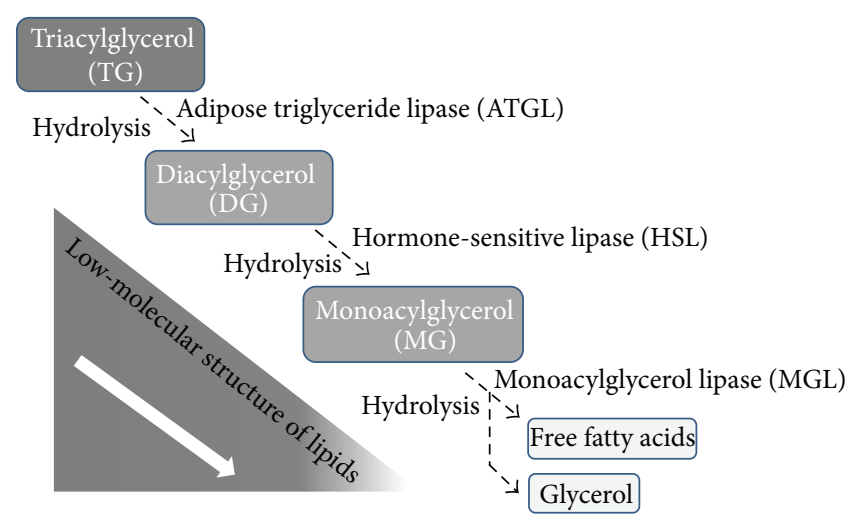

FIGURE 2: ATGL acts exclusively on the hydrolysis of TG. A major component of HSL activity depends on the generation of DG, a substrate from the action of ATGL. Finally, MGL acts to liberate glycerol and the final FFA.

regulation of enzyme activity and is closely associated with the catabolism of adipocytes.

\section{Regulation of Lipolysis via the Coordinated Action of Lipases and Cofactors}

The discovery of perilipin 1 provided proof of cofactors which exist in the cytoplasm and on the lipid droplet surface [34]. Perilipin 1 is the founding member of the perilipin, adipophilin, and TIP47 family (referred to as the PAT/perilipin family protein) of lipid droplet-coated proteins [35] and is expressed mostly in white adipose tissue, where it coats lipid droplets, and in steroidogenic tissue [36]. Perilipin 1 has as many as six phosphorylation sites (Ser81, Ser222, Ser276, Ser433, Ser492, and Ser517) in adipocytes by PKA [37-40]. Several studies have reported that perilipin 1 is multifunctional and is capable of reducing basal lipolysis via combining HSL with lipid droplets to form a barrier [41] and promotes the lipolysis movement of perilipin 1 away from fat droplets [42] through lipasedependent and -independent mechanisms [43]. Moreover, 


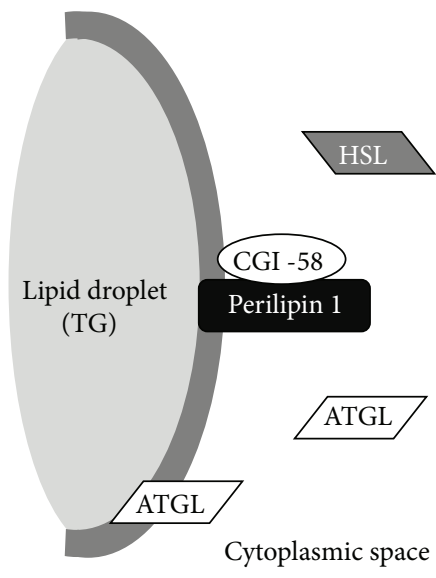

(a) Basal and inactivated conditions

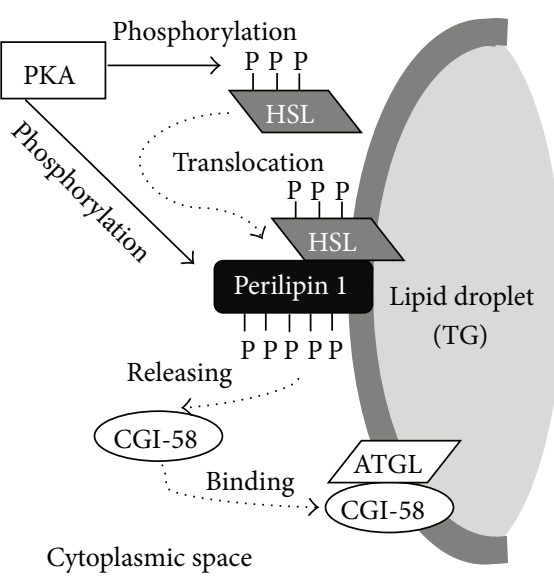

(b) Hormone-activated conditions

FIGURE 3: Under basal and inactivated conditions, perilipin 1 and CGI-58 form a complex on the surface of lipid droplets (a). On the other hand, PKA activation leads to the phosphorylation of both HSL and perilipin 1, resulting in HSL and perilipin 1 forming a complex on the surface of lipid droplets. Released CGI-58 from phosphorylated perilipin 1 binds to ATGL to induce lipolysis (b).

the CGI-58, also known as $\alpha / \beta$ hydrolase domain-containing protein 5 (ABHD5), was found to increase the TG hydrolase activity of ATGL owing to a direct interaction with ATGL proteins [44]. CGI-58 also has the ability to be associated with perilipin $1[35,45-47]$, demonstrating that the localizations of both perilipin 1 and CGI-58 are centrally involved in the organization and regulation of lipolytic effector interactions in both basal and hormone-stimulated states. The conceptual consensus schema is described below (Figure 3). Under basal conditions, CGI-58 localizes on the lipid droplet surfaces with perilipin 1, although ATGL exists predominantly within the cytoplasm [48], resulting in an attenuation of the interaction of ATGL with CGI-58 [49]. HSL is also located entirely in the cytoplasm, where it is nonphosphorylated and removed from lipid droplets, thereby reducing the hydrolysis activity of TG in adipocytes [36]. In contrast, hormonal activation of $\beta$-ARs-PKA provokes the association of CGI-58 with ATGL in fragmented lipid droplets following the rapid, within minutes, dissociation of PKA-phosphorylated perilipin 1 at Ser517 and CGI-58 $[38,48]$. During that time, PKA promotes both phosphorylation and translocation of phosphorylated HSL at Ser659 and Ser660 from the cytoplasm to lipid droplets [50], and, in turn, perilipin 1 acts as a scaffold protein to bind HSL with lipid droplets [34], which results in an inducement of the maximal lipolytic response. Thus, serial modification events of lipolytic molecules, which support the localization of lipases, would play a critical role in the adaptive alteration of the lipolytic response in white adipocytes by physical exercise.

\section{Effect of ET on the Number of $\beta$-ARs, Which Is the First Step in the Mobilization of the Lipolytic Cascade}

As mentioned in the above sections, stimulation of the $\beta$ ARs-AC system in white adipocytes results in a change in intracellular cAMP production and in the subsequent activation of PKA. Thus, an increase in the number of the $\beta$-ARs, which are expressed on the cell surfaces, would be expected to play a key role in the upregulation of lipolysis that is caused by ET. In ET, however, there is a small amount of evidence that indicates no change in the number of $\beta$-ARs [51, 52], which are measured by hydrophobic ligands, compared to the primary adipocytes of sedentary control rats. Moreover, investigation using hydrophilic ligands has demonstrated that the level of $\beta$-ARs on cell surfaces is significantly decreased due to ET in rat [53], indicating that the level of $\beta$-ARs by ET, at least in part, might be internalized into the cytoplasm rather than being increased on the cell surfaces. In addition, in rat, it has been shown that enhancement of $\beta$-ARs-AC coupling is observed in white adipocytes from ET $[54,55]$. These results indicate that an ET-induced increase in lipolysis is not dependent on the number of $\beta$-ARs but rather the enhancement of the association efficiency of both $\beta$-ARs and Gs proteins. Thus, an ET-induced enhancement of lipolysis might be mediated by an adaptive alteration in post $\beta$-ARs.

Under ET, repeat exposure of high levels of plasma catecholamines during bouts of daily exercise might be likely to trigger downregulation and change the localization of $\beta$-ARs into the cytoplasm in white adipocytes. Some very elegant studies conducted by Shenoy and coworkers [56] have shown that $\beta_{2}$-ARs have a functional turnover cycle from the cellular surface to the cytosol via ubiquitination in a catecholamine dose-dependent manner. Of note, the adaptive change of adipocytes in response to ET appears to be the result of the integrative effect of bouts of acute exercise. Therefore, an understanding of the acute exerciseinduced trafficking events of $\beta_{2}$-AR would support the clarification of adaptive moderation of $\beta$-ARs by ET. In rat primary epididymal adipocytes, our results obtained from acute exercise demonstrated that localization of $\beta_{2}$-ARs on the cell surface was upregulated at least 3 hours after exercise with reduced interaction of $\beta$-arrestin 2 and $\beta_{2}$-AR, whereas it returned to the sedentary control levels 24 hours after 

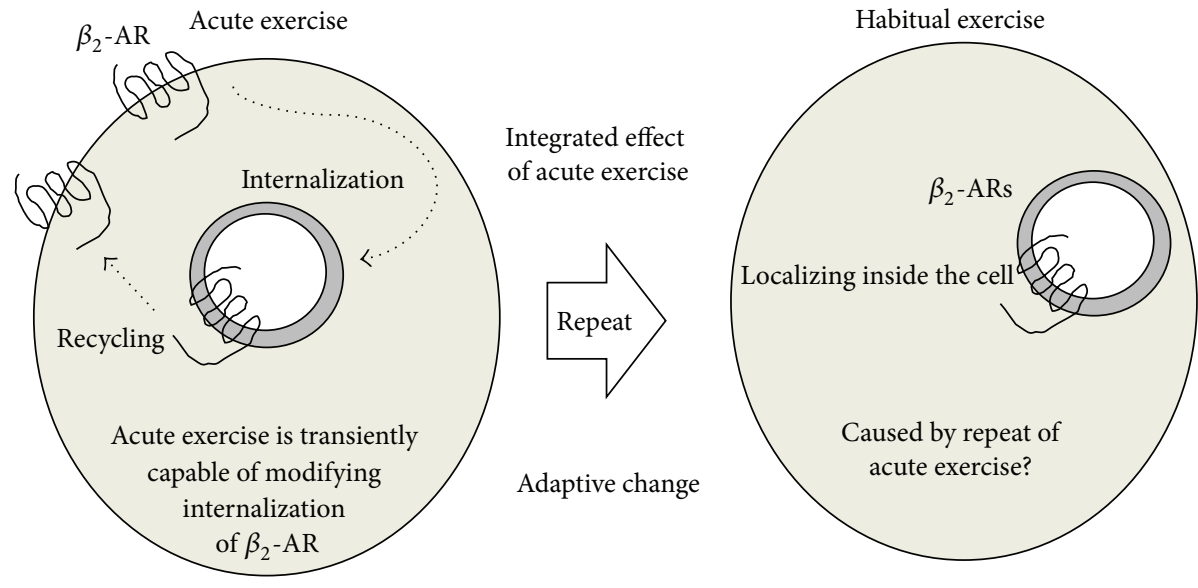

FIGURE 4: Internalization of $\beta_{2}$-ARs from plasma membrane to intracellular space is modified by acute exercise in white adipocytes. HEinduced increase in the localizations of $\beta$-ARs into the cytoplasm might be a result of, at least in part, a mobilization of the trafficking of $\beta_{2}$-ARs, which is caused by daily repeated bouts of acute exercise.

exercise [57] (Figure 4). Loss of the combination of $\beta$-arrestin 2 and $\beta_{2}$-AR resulted in a reduction in $\beta_{2}$-AR ubiquitination, which thereby attenuated the internalization of $\beta_{2}$-ARs into the cytoplasm. However, internalized $\beta_{2}$-ARs were capable of quick recycling on the cell surface [58]. Together, the turnover of $\beta_{2}$-ARs that was induced by every single bout of exercise might have been the result of the reduced levels of $\beta_{2}$-ARs on the cell surfaces by ET, because, in this instance, there were no changes in the total amount of $\beta$-AR [51-53] (Figure 4).

\section{Adaptive Alteration in G-Proteins by Habitual Physical Exercise}

It is known that both Gs protein $\alpha$ subunit (Gs $\alpha$ ) and Gi protein $\alpha$ subunit (Gi $\alpha$ ), which are dissociated from $\beta$ - and $\gamma$-subunits by stimulation of $\alpha$ - and $\beta$-ARs, play key roles in the synergistic action of AC in white adipocytes. ET reportedly provoked a significant increase in AC activity of rat white adipocytes [59], accompanied by a decrease in the levels of Gi $\alpha$ protein, but caused no change in the levels of Gs $\alpha$ proteins in rat white adipocytes [60]. Moreover, ET significantly decreased the levels of Gi $\alpha 2$ protein, which predominantly inhibits AC activity, in rat white adipocytes [61] and in rat pancreatic islets [62]. These results indicate that ET positively regulates the signal transduction systems through the inhibition of Gi $\alpha$ function in adipose cells, which leads to the activation of AC. However, the mechanism(s) by which ET induces the downregulation of Gi $\alpha 2$ protein is unknown. In our previous study, acute exercise transiently downregulated the levels of Gi $\alpha 2$ proteins at least 3 hours after exercise via ubiquitin-proteasomal degradation machinery in rat white adipocytes [63] (Figure 5), suggesting the possibility that the downregulation of Gi $\alpha 2$ protein by ET might also be associated with acute exercise-induced proteolysis action, because ET is often defined by a repeat of bouts of acute exercise. Indeed, it is known that promotion of the ubiquitin-proteasome system is dependent on intracellular ATP, which is produced in several cells during exercise
[9]. Moreover, the levels of MuRF-1, a muscle-specific E3 ligase, are reportedly reduced by ET in chronic heart failure patients [64]. Thus, in ET, the conspicuous effect of exercise on cellular energy production and selective transcriptional systems might be one of the triggers for the downregulation of Gi $\alpha 2$ proteins in white adipocytes (Figure 5). Such a conclusion, however, requires further study.

\section{Manipulation of Lipolytic Molecules by Physical Exercise to Supply Energy}

An understanding of the regulatory mechanisms underlying basal and hormone-stimulated lipolysis in adipocytes has evolved in recent years. However, little is known about the effect of ET on the molecular behavior of lipolytic proteins, that is, perilipin 1 and CGI-58, in white adipocytes. In rat, ET studies have shown no change in intracellular cAMP accumulation in white adipocytes compared with a sedentary control [51], suggesting the possibility that the molecular behavior of lipolytic proteins, which occur in the cell, plays a key role in the HE-induced enhancement of the lipolytic response. Indeed, our previous study indicated that white adipocytes obtained from ET rat enhance the levels of catalytic subunits of PKA proteins and PKA-anchoring protein 150 (AKAP150), which promotes the binding of PKA and its substrate, with activation of both PKA and HSL in the lipid droplet fraction of adipocyte homogenate [65]. These results would explain the phenomena whereby the ET-induced anchoring of AKAP150 to PKA enhances the magnitude of cAMP signaling in white adipocytes, even if accumulations of intracellular cAMP fail to increase as a result of ET. In rat, levels of HSL in adipocytes reportedly are upregulated by ET despite obesity [12] or normal circumstances in an individual [66], suggesting that the AKAP150-mediated enhancing action of PKA easily provokes the interaction of PKA with HSL, thereby activating the phosphorylation of HSL in cytoplasmic space. However, in rat white adipocytes, the phosphorylation of HSL by acute exercise is accompanied 

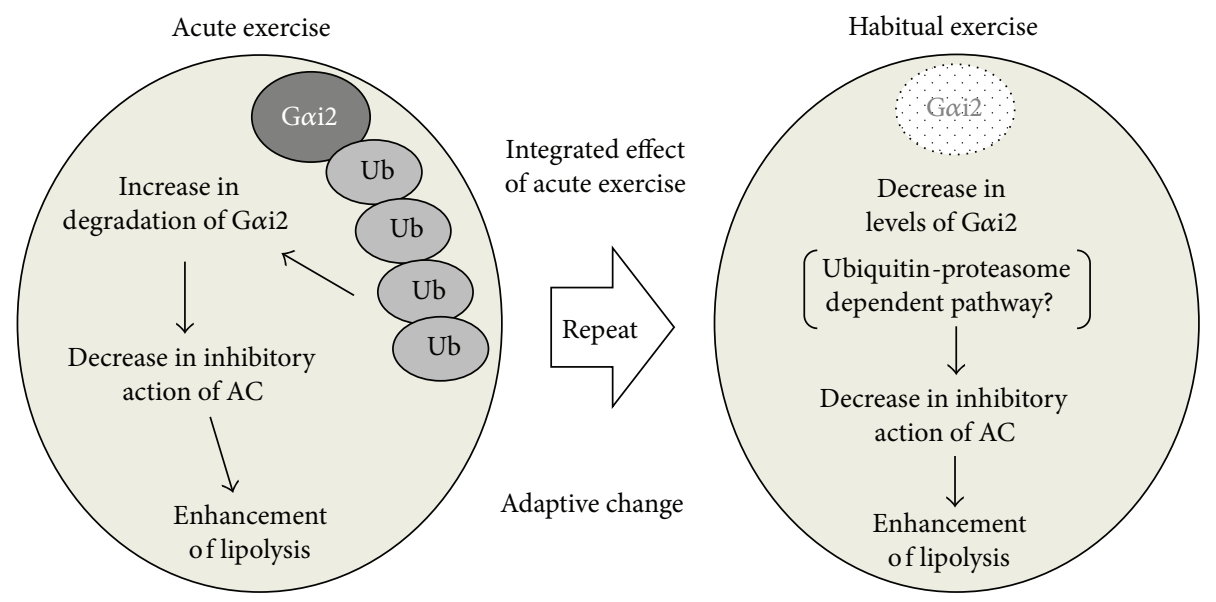

FIGURE 5: In white adipocytes, acute exercise accelerates the degradation of G $\alpha$ i2 proteins through the ubiquitin-proteasome system during, and at least 3 hours after, exercise. This mechanism might become a trigger for habitual decreases in the levels of G $\alpha$ i2 by ET.

by an increase in intracellular cAMP production [63]. Thus, the functional alteration in AKAP150 might play a critical role in the adaptive augmentation of lipolytic responses by ET in white adipocytes.

Alsted and colleagues were the first to report that levels of ATGL protein are significantly increased in human skeletal muscle by ET [67], although adipose tissue is used to identify ATGL [13]. It is noteworthy that the deletion of ATGL in mice impairs exercise performance [68] and that ATGL knockout mice show no increase in circulating FFA levels during exercise [69], suggesting that a molecular change in ATGL, as well as HSL, plays a role in supplying FFA from white adipocytes during physical exercise as a fuel for metabolism. To date, however, little is known about the effect of ET on the molecular changes of ATGL in white adipocytes. Recently, in rat, we demonstrated that mRNA, protein levels of ATGL, and HSL proteins all are upregulated by ET and that DNA-binding activities of peroxisome proliferation-activated receptor- $\gamma 2$ (PPAR- $\gamma 2$ ) are closely associated with the ETinduced upregulation of ATGL [70]. Under these conditions, the binding of CGI-58 to ATGL was significantly increased on the lipid droplets with dissociations of CGI-58 and perilipin 1. These results indicate that the ET-induced acceleration of lipolytic responses is, at least in part, mediated by the hyperfunction of newly synthesized protein via the transcriptional activation of ATGL. Meanwhile, there is no evidence as to whether PKA-mediated phosphorylation of ATGL is involved in the hydrolysis of TG by ET, although at least one previous study has demonstrated that the increased phosphorylation of ATGL at Ser406, a PKA-mediated phosphorylation site, during both fasting and moderate single bouts of exercise is associated with an elevated rate of lipolysis in mice [71]. In our pilot study, ET showed higher levels of phosphorylated ATGL compared with the sedentary control in rat epididymal white adipocytes (unpublished data). These results suggest the possibility that ET might cause a phosphorylation-provoked conformational change in the protein structures of ATGL, which might result in a hypercombination of CGI-58 on lipid droplets [70], thereby enhancing the lipolytic responses in rat white adipocytes. In conclusion, several results have indicated that localization and/or phosphorylation of lipolytic molecules, such as perilipin 1, CGI-58, HSL, and ATGL, has a central function in the ET-induced adaptive alteration of lipolysis in white adipocytes and that the AKAP150-mediated activation of PKA also plays a key role in this mechanism (Figure 6).

\section{Conclusion}

It is well documented that exercise of moderate intensity accelerates the lipolytic responses in human white adipocytes [72-74]. In this review, studies showing both ET and acute exercise of light to moderate intensity $[50-52,56,58-63$, $65,66,70]$ indicated that moderate intensity of ET clearly provokes an enhancement of lipolysis in white adipocytes with an orchestral alteration in lipolytic molecules in a positive manner. However, little is known about the highintensity exercise-induced behavior of lipolytic molecules in white adipocytes so far. Further studies are required to clarify this point.

A clarification of $\mathrm{HE}$-induced molecular changes in a lipolytic cascade would apply not only to the prevention of obesity but also to the elucidation of a methodology for advances in exercise effectiveness. However, in white adipocytes no complete evidence exists to explain the mechanism(s) underlying the HE-induced adaptive changes in lipolysis. In particular, there are no new insights into the alterations in $\mathrm{G}$ protein-coupled receptors, nor into the family of G-proteins and related modification events brought about by $\mathrm{HE}$, although a few results obtained in our studies have shown that ubiquitin-proteasome system plays a role in acute exercise-mediated amplification of the lipolytic cascade via the expression levels of both $\beta_{2}$-AR and Gi $\alpha 2$ proteins. However, it is noteworthy that more than 200 genes that regulate lipid droplet morphology have been identified in Drosophila [75], suggesting that new molecules, which are unknown in mammalian species, would be related to the regulation of 


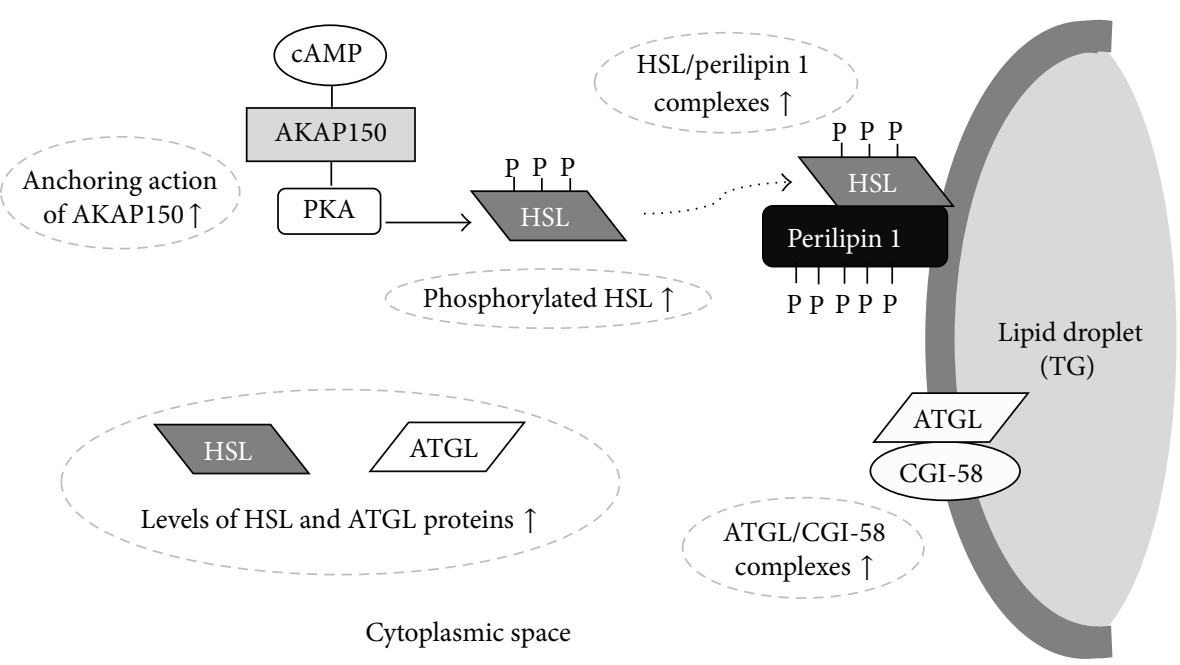

FIGURE 6: Summary of HE-induced adaptive changes of lipolytic molecules in white adipocytes. ET constantly promotes the expression levels of ATGL and HSL proteins. These conditions are likely to give rise to the stimulation of lipolytic responses through adaptive changes in molecules, such as increases in the anchoring action of AKAP150, higher levels of phosphorylated HSL, and augmentation of the formation of a complex of both HSL/perilipin 1 and ATGL/CGI-58 on the surface of lipid droplet. $\uparrow$ : upregulation of function and expression levels of each molecule.

lipolytic events in white adipocytes with or without exercise. In the near future, the search for new molecules with the aim of elucidating their functions in an exercise-specific manner will shed new light on the calculations of a highly effective lipolytic system of exercise and will enhance the biological understanding of white adipocytes as a "vehicle" for the storage and supply of energy.

\section{Abbreviations}

$\begin{array}{ll}\text { ET: } & \text { Continuous exercise training } \\ \text { GPCRs: } & \text { G-protein coupled receptors } \\ \text {-AR: } & \text { Adrenergic receptor } \\ \text {-R: } & \text { Receptor } \\ \text { Gs } \alpha: & \text { Gs protein } \alpha \text { subunit } \\ \text { Gi } \alpha: & \text { Gi protein } \alpha \text { subunit } \\ \text { AC: } & \text { Adenylyl cyclase } \\ \text { P: } & \text { Phosphorylation } \\ \text { PKA: } & \text { cAMP-dependent protein kinase A } \\ \text { TG: } & \text { Triacylglycerol } \\ \text { DG: } & \text { Diacylglycerol } \\ \text { MG: } & \text { Monoacylglycerol } \\ \text { IRS-1: } & \text { Insulin receptor substrate-1 } \\ \text { PI3-K: } & \text { Phosphatidylinositol 3-kinase } \\ \text { PKB: } & \text { Protein kinase B } \\ \text { PDE-3B: } & \text { Phosphodiesterase-3B } \\ \text { HSL: } & \text { Hormone-sensitive lipase } \\ \text { ATGL: } & \text { Adipose triglyceride lipase } \\ \text { MGL: } & \text { Monoacylglycerol lipase } \\ \text { AMPK: } & \text { AMP activated protein kinase } \\ \text { CGI-58: } & \text { Comparative gene identification-58 } \\ \text { PAT/perilipin } & \text { Perilipin/perilipin 1, } \\ \text { family proteins: } & \text { adipophilin/perilipin 2, } \\ & \text { TIP47/perilipin 3, S3-12/perilipin 4, } \\ & \text { and muscle lipid droplet } \\ & \text { protein/perilipin 5 family proteins }\end{array}$

\author{
AKAP150: $\quad$ PKA-anchoring protein 150 \\ PPAR- $\gamma 2$ : $\quad$ Peroxisome proliferation-activated \\ receptor- $\gamma 2$.
}

\section{Conflict of Interests}

The authors have declared that there is no conflict of interests.

\section{Acknowledgment}

This work was supported in part by Grant-in-Aid for Scientific Research from the Japan Ministry of Education, Culture, Sports, Science and Technology.

\section{References}

[1] B. M. Popkin and M. M. Slining, "New dynamics in global obesity facing low- and middle-income countries," Obesity Reviews, vol. 14, supplement 2, pp. 11-20, 2013.

[2] J. Borén, M.-R. Taskinen, S.-O. Olofsson, and M. Levin, "Ectopic lipid storage and insulin resistance: a harmful relationship," Journal of Internal Medicine, vol. 274, no. 1, pp. 25-40, 2013.

[3] G. Perseghin, "Muscle lipid metabolism in the metabolic syndrome," Current Opinion in Lipidology, vol. 16, no. 4, pp. 416420, 2005.

[4] P. Vermathen, P. Saillen, A. Boss, M. Zehnder, and C. Boesch, "Skeletal muscle ${ }^{1} \mathrm{H}$ MRSI before and after prolonged exercise. I. muscle specific depletion of intramyocellular lipids," Magnetic Resonance in Medicine, vol. 68, no. 5, pp. 1357-1367, 2012.

[5] K. Louche, P.-M. Badin, E. Montastier et al., "Endurance exercise training up-regulates lipolytic proteins and reduces triglyceride content in skeletal muscle of obese subjects," The Journal of Clinical Endocrinology and Metabolism, vol. 98, no. 12, pp. 4863-4871, 2013. 
[6] G.-J. van der Heijden, Z. J. Wang, Z. D. Chu et al., "A 12-week aerobic exercise program reduces hepatic fat accumulation and insulin resistance in obese, hispanic adolescents," Obesity, vol. 18, no. 2, pp. 384-390, 2010.

[7] P. Mauriege, J. Galitzky, M. Berlan, and M. Lafontan, "Heterogeneous distribution of beta and alpha-2 adrenoceptor binding sites in human fat cells from various fat deposits: functional consequences," European Journal of Clinical Investigation, vol. 17, no. 2, pp. 156-165, 1987.

[8] M. Lafontan and M. Berlan, "Fat cell adrenergic receptors and the control of white and brown fat cell function," Journal of Lipid Research, vol. 34, no. 7, pp. 1057-1091, 1993.

[9] P. Arner, E. Kriegholm, P. Engfeldt, and J. Bolinder, "Adrenergic regulation of lipolysis in situ at rest and during exercise," The Journal of Clinical Investigation, vol. 85, no. 3, pp. 893-898, 1990.

[10] I. Castan, P. Valet, N. Quideau et al., "Antilipolytic effects of $\alpha 2$-adrenergic agonists, neuropeptide $\mathrm{Y}$, adenosine, and PGE1 in mammal adipocytes," The American Journal of Physiology: Regulatory Integrative and Comparative Physiology, vol. 266, no. 4, pp. R1141-R1147, 1994.

[11] J. E. Campbell, S. Fediuc, T. J. Hawke, and M. C. Riddell, "Endurance exercise training increases adipose tissue glucocorticoid exposure: adaptations that facilitate lipolysis," Metabolism: Clinical and Experimental, vol. 58, no. 5, pp. 651660, 2009.

[12] T. Hashimoto, K. Sato, and M. Iemitsu, "Exercise-inducible factors to activate lipolysis in adipocytes," Journal of Applied Physiology, vol. 115, no. 2, pp. 260-267, 2013.

[13] R. Zimmermann, J. G. Strauss, G. Haemmerle et al., "Fat mobilization in adipose tissue is promoted by adipose triglyceride lipase," Science, vol. 306, no. 5700, pp. 1383-1386, 2004.

[14] P. E. Bickel, J. T. Tansey, and M. A. Welte, "PAT proteins, an ancient family of lipid droplet proteins that regulate cellular lipid stores," Biochimica et Biophysica Acta, vol. 1791, no. 6, pp. 419-440, 2009.

[15] T. Yamaguchi, "Crucial role of CGI-58/alpha/beta hydrolase domain-containing protein 5 in lipid metabolism," Biological \& Pharmaceutical Bulletin, vol. 33, no. 3, pp. 342-345, 2010.

[16] L.-J. Syu and A. R. Saltiel, "Lipotransin: a novel docking protein for hormone-sensitive lipase," Molecular Cell, vol. 4, no. 1, pp. 109-115, 1999.

[17] D. Langin and P. Arner, "Importance of TNF $\alpha$ and neutral lipases in human adipose tissue lipolysis," Trends in Endocrinology and Metabolism, vol. 17, no. 8, pp. 314-320, 2006.

[18] R. E. Duncan, M. Ahmadian, K. Jaworski, E. Sarkadi-Nagy, and H. S. Sul, "Regulation of lipolysis in adipocytes," Annual Review of Nutrition, vol. 27, pp. 79-101, 2007.

[19] J. Gómez-Ambrosi, G. Frühbeck, M. Aguado, F. I. Milagro, J. Margareto, and A. J. Martínez, "Divergent effects of an alpha2adrenergic antagonist on lipolysis and thermogenesis: interactions with a beta3-adrenergic agonist in rats," International Journal of Molecular Medicine, vol. 8, no. 1, pp. 103-109, 2001.

[20] B. B. Fredholm, "Effect of adenosine, adenosine analogues and drugs inhibiting adenosine inactivation on lipolysis in rat fat cells," Acta Physiologica Scandinavica, vol. 102, no. 2, pp. 191-198, 1978.

[21] R. P. Robertson and S. A. Little, "Down-regulation of prostaglandin E receptors and homologous desensitization of isolated adipocytes," Endocrinology, vol. 113, no. 5, pp. 1732-1738, 1983.
[22] R. C. Honnor, G. S. Dhillon, and C. Londos, "cAMP-dependent protein kinase and lipolysis in rat adipocytes. I. Cell preparation, manipulation, and predictability in behavior," The Journal of Biological Chemistry, vol. 260, no. 28, pp. 15122-15129, 1985.

[23] R. C. Honnor, G. S. Dhillon, and C. Londos, "cAMP-dependent protein kinase and lipolysis in rat adipocytes. II. Definition of steady-state relationship with lipolytic and antilipolytic modulators," The Journal of Biological Chemistry, vol. 260, no. 28, pp. 15130-15138, 1985.

[24] A. S. Greenberg, W.-J. Shen, K. Muliro et al., "Stimulation of lipolysis and hormone-sensitive lipase via the extracellular signal-regulated kinase pathway," The Journal of Biological Chemistry, vol. 276, no. 48, pp. 45456-45461, 2001.

[25] C. Holm, "Molecular mechanisms regulating hormonesensitive lipase and lipolysis," Biochemical Society Transactions, vol. 31, part 6, pp. 1120-1124, 2003.

[26] J. J. Egan, A. S. Greenberg, M.-K. Chang, S. A. Wek, M. C. Moos Jr., and C. Londos, "Mechanism of hormone-stimulated lipolysis in adipocytes: translocation of hormone-sensitive lipase to the lipid storage droplet," Proceedings of the National Academy of Sciences of the United States of America, vol. 89, no. 18, pp. 8537-8541, 1992.

[27] S. Enoksson, E. Degerman, E. Hagström-Toft, V. Large, and P. Arner, "Various phosphodiesterase subtypes mediate the in vivo antilipolytic effect of insulin on adipose tissue and skeletal muscle in man," Diabetologia, vol. 41, no. 5, pp. 560-568, 1998.

[28] P. Strålfors and R. C. Honnor, "Insulin-induced dephosphorylation of hormone-sensitive lipase. Correlation with lipolysis and cAMP-dependent protein kinase activity," European Journal of Biochemistry, vol. 182, no. 2, pp. 379-385, 1989.

[29] M. J. Watt, A. G. Holmes, S. K. Pinnamaneni et al., "Regulation of HSL serine phosphorylation in skeletal muscle and adipose tissue," The American Journal of Physiology -Endocrinology and Metabolism, vol. 290, no. 3, pp. E500-E508, 2006.

[30] J. A. Villena, S. Roy, E. Sarkadi-Nagy, K.-H. Kim, and S. S. Hei, "Desnutrin, an adipocyte gene encoding a novel patatin domain-containing protein, is induced by fasting and glucocorticoids: ectopic expression of desnutrin increases triglyceride hydrolysis," The Journal of Biological Chemistry, vol. 279, no. 45, pp. 47066-47075, 2004.

[31] C. M. Jenkins, D. J. Mancuso, W. Yan, H. F. Sims, B. Gibson, and R. W. Gross, "Identification, cloning, expression, and purification of three novel human calcium-independent phospholipase $\mathrm{A}_{2}$ family members possessing triacylglycerol lipase and acylglycerol transacylase activities," The Journal of Biological Chemistry, vol. 279, no. 47, pp. 48968-48975, 2004.

[32] E. Smirnova, E. B. Goldberg, K. S. Makarova, L. Lin, W. J. Brown, and C. L. Jackson, "ATGL has a key role in lipid droplet/adiposome degradation in mammalian cells," The EMBO Reports, vol. 7, no. 1, pp. 106-113, 2006.

[33] R. Bartz, J. K. Zehmer, M. Zhu et al., "Dynamic activity of lipid droplets: protein phosphorylation and GTP-mediated protein translocation," Journal of Proteome Research, vol. 6, no. 8, pp. 3256-3265, 2007.

[34] D. L. Brasaemle, "The perilipin family of structural lipid droplet proteins: stabilization of lipid droplets and control of lipolysis," The Journal of Lipid Research, vol. 48, no. 12, pp. 2547-2559, 2007.

[35] D. L. Brasaemle and N. E. Wolins, "Packaging of fat: an evolving model of lipid droplet assembly and expansion," The Journal of Biological Chemistry, vol. 287, no. 4, pp. 2273-2279, 2012. 
[36] A. S. Greenberg, J. J. Egan, S. A. Wek, N. B. Garty, E. J. Blanchette-Mackie, and C. Londos, "Perilipin, a major hormonally regulated adipocyte-specific phosphoprotein associated with the periphery of lipid storage droplets," The Journal of Biological Chemistry, vol. 266, no. 17, pp. 11341-11346, 1991.

[37] H. Miyoshi, J. W. Perfield II, S. C. Souza et al., "Control of adipose triglyceride lipase action by serine 517 of perilipin A globally regulates protein kinase a-stimulated lipolysis in adipocytes," The Journal of Biological Chemistry, vol. 282, no. 2, pp. 996-1002, 2007.

[38] H. Miyoshi, S. C. Souza, H.-H. Zhang et al., "Perilipin promotes hormone-sensitive lipase-mediated adipocyte lipolysis via phosphorylation-dependent and -independent mechanisms," The Journal of Biological Chemistry, vol. 281, no. 23, pp. 15837-15844, 2006.

[39] C. Sztalryd, G. Xu, H. Dorward et al., "Perilipin A is essential for the translocation of hormone-sensitive lipase during lipolytic activation," The Journal of Cell Biology, vol. 161, no. 6, pp. 10931103, 2003.

[40] J. T. Tansey, A. M. Huml, R. Vogt et al., "Functional studies on native and mutated forms of perilipins: a role in protein kinase a-mediated lipolysis of triacylglycerols in Chinese hamster ovary cells," The Journal of Biological Chemistry, vol. 278, no. 10, pp. 8401-8406, 2003.

[41] J. T. Tansey, C. Sztalryd, J. Gruia-Gray et al., "Perilipin ablation results in a lean mouse with aberrant adipocyte lipolysis, enhanced leptin production, and resistance to diet-induced obesity," Proceedings of the National Academy of Sciences of the United States of America, vol. 98, no. 11, pp. 6494-6499, 2001.

[42] G. M. Clifford, F. B. Kraemer, S. J. Yeaman, and R. G. Vernon, "Translocation of hormone-sensitive lipase and perilipin upon lipolytic stimulation during the lactation cycle of the rat," Metabolism: Clinical and Experimental, vol. 50, no. 11, pp. 12641269, 2001.

[43] D. L. Brasaemle, V. Subramanian, A. Garcia, A. Marcinkiewicz, and A. Rothenberg, "Perilipin A and the control of triacylglycerol metabolism," Molecular and Cellular Biochemistry, vol. 326, no. 1-2, pp. 15-21, 2009.

[44] A. Lass, R. Zimmermann, G. Haemmerle et al., "Adipose triglyceride lipase-mediated lipolysis of cellular fat stores is activated by CGI-58 and defective in Chanarin-Dorfman Syndrome," Cell Metabolism, vol. 3, no. 5, pp. 309-319, 2006.

[45] V. Subramanian, A. Rotlienberg, C. Gomez et al., "Perilipin A mediates the reversible binding of CGI-58 to lipid droplets in 3T3-L1 adipocytes," The Journal of Biological Chemistry, vol. 279, no. 40, pp. 42062-42071, 2004.

[46] T. Yamaguchi, N. Omatsu, S. Matsushita, and T. Osumi, "CGI58 interacts with perilipin and is localized to lipid droplets: possible involvement of CGI-58 mislocalization in ChanarinDorfman syndrome," The Journal of Biological Chemistry, vol. 279, no. 29, pp. 30490-30497, 2004.

[47] J. G. Granneman, H.-P. H. Moore, R. Krishnamoorthy, and M. Rathod, "Perilipin controls lipolysis by regulating the interactions of AB-hydrolase containing 5 (Abhd5) and adipose triglyceride lipase (Atgl)," The Journal of Biological Chemistry, vol. 284, no. 50, pp. 34538-34544, 2009.

[48] J. G. Granneman, H.-P. H. Moore, R. L. Granneman, A. S. Greenberg, M. S. Obin, and Z. Zhu, "Analysis of lipolytic protein trafficking and interactions in adipocytes," The Journal of Biological Chemistry, vol. 282, no. 8, pp. 5726-5735, 2007.

[49] T. Yamaguchi, N. Omatsu, E. Morimoto et al., "CGI-58 facilitates lipolysis on lipid droplets but is not involved in the vesiculation of lipid droplets caused by hormonal stimulation," Journal of Lipid Research, vol. 48, no. 5, pp. 1078-1089, 2007.

[50] C.-L. Su, C. Sztalryd, J. A. Contreras, C. Holm, A. R. Kimmel, and C. Londos, "Mutational analysis of the hormone-sensitive lipase translocation reaction in adipocytes," The Journal of Biological Chemistry, vol. 278, no. 44, pp. 43615-43619, 2003.

[51] L. Bukowiecki, J. Lupien, N. Follea, A. Paradis, D. Richard, and J. LeBlanc, "Mechanism of enhanced lipolysis in adipose tissue of exercise-trained rats.," The American Journal of Physiology, vol. 239, no. 6, pp. E422-E429, 1980.

[52] R. E. Shepherd and M. D. Bah, "Cyclic AMP regulation of fuel metabolism during exercise: regulation of adipose tissue lipolysis during exercise," Medicine and Science in Sports and Exercise, vol. 20, no. 6, pp. 531-538, 1988.

[53] K. Suda, T. Izawa, T. Komabayashi, M. Tsuboi, and S. Era, "Effect of insulin on adipocyte lipolysis in exercise-trained rats," Journal of Applied Physiology, vol. 74, no. 6, pp. 2935-2939, 1993.

[54] R. S. Williams and T. Bishop, "Enhanced receptor-cyclase coupling and augmented catecholamine-stimulated lipolysis in exercising rats," The American Journal of PhysiologyEndocrinology and Metabolism, vol. 243, no. 5, pp. E345-E351, 1982.

[55] T. Izawa, T. Komabayashi, M. Tsuboi, E. Koshimizu, and K. Suda, "Augmentation of catecholamine-stimulated [3H]GDP release in adipocyte membranes from exercise-trained rats," The Japanese Journal of Physiology, vol. 36, no. 5, pp. 1039-1045, 1986.

[56] S. K. Shenoy, P. H. McDonald, T. A. Kohout, and R. J. Lefkowitz, "Regulation of receptor fate by ubiquitination of activated $\beta 2$ adrenergic receptor and $\beta$-arrestin," Science, vol. 294, no. 5545, pp. 1307-1313, 2001.

[57] J. Ogasawara, M. Sanpei, N. Rahman et al., “ $\beta$-adrenergic receptor trafficking by exercise in rat adipocytes: roles of G-proteincoupled receptor kinase-2, $\beta$-arrestin-2, and the ubiquitinproteasome pathway," The FASEB Journal, vol. 20, no. 2, pp. 350352, 2006.

[58] E. Macia, M. Partisani, O. Paleotti, F. Luton, and M. Franco, "Arf6 negatively controls the rapid recycling of the $\beta 2$ adrenergic receptor," Journal of Cell Science, vol. 125, no. 17, pp. 40264035, 2012.

[59] T. Izawa, T. Komabayashi, T. Mochizuki, K. Suda, and M. Tsuboi, "Enhanced coupling of adenylate cyclase to lipolysis in permeabilized adipocytes from trained rats," Journal of Applied Physiology, vol. 71, no. 1, pp. 23-29, 1991.

[60] T. Izawa, T. Komabayashi, S. Shinoda, K. Suda, M. Tsuboi, and E. Koshimizu, "Possible mechanism of regulating adenylate cyclase activity in adipocyte membranes from exercise-trained male rats," Biochemical and Biophysical Research Communications, vol. 151, no. 3, pp. 1262-1298, 1988.

[61] J. L. Nieto, I. D. Laviada, A. Guillén, and A. Haro, "Adenylyl cyclase system is affected differently by endurance physical training in heart and adipose tissue," Biochemical Pharmacology, vol. 51, no. 10, pp. 1321-1329, 1996.

[62] Y. Urano, T. Sakurai, H. Ueda, J. Ogasawara, M. Takei, and T. Izawa, "Desensitization of the inhibitory effect of norepinephrine on insulin secretion from pancreatic islets of exercise-trained rats," Metabolism: Clinical and Experimental, vol. 53, no. 11, pp. 1424-1432, 2004.

[63] J. Ogasawara, T. Sakurai, N. Rahman et al., "Acute exercise alters $\mathrm{G} \alpha \mathrm{i} 2$ protein expressions through the ubiquitin-proteasome proteolysis pathway in rat adipocytes," Biochemical and Biophysical Research Communications, vol. 323, no. 3, pp. 1109-1115, 2004 . 
[64] A. Ciechanover, "Intracellular protein degradation: from a vague idea thru the lysosome and the ubiquitin-proteasome system and onto human diseases and drug targeting," Biochimica et Biophysica Acta-Proteins and Proteomics, vol. 1824, no. 1, pp. 3-13, 2012.

[65] S. Gielen, M. Sandri, I. Kozarez et al., "Exercise training attenuates MuRF-1 expression in the skeletal muscle of patients with chronic heart failure independent of age: the randomized leipzig exercise intervention in chronic heart failure and aging catabolism study," Circulation, vol. 125, no. 22, pp. 2716-2727, 2012.

[66] S. Nomura, H. Kawanami, H. Ueda, T. Kizaki, H. Ohno, and T. Izawa, "Possible mechanisms by which adipocyte lipolysis is enhanced in exercise-trained rats," Biochemical and Biophysical Research Communications, vol. 295, no. 2, pp. 236-242, 2002.

[67] T. J. Alsted, L. Nybo, M. Schweiger et al., "Adipose triglyceride lipase in human skeletal muscle is upregulated by exercise training," American Journal of Physiology: Endocrinology and Metabolism, vol. 296, no. 3, pp. E445-E453, 2009.

[68] E. Huijsman, C. van de Par, C. Economou et al., "Adipose triacylglycerol lipase deletion alters whole body energy metabolism and impairs exercise performance in mice," The American Journal of Physiology -Endocrinology and Metabolism, vol. 297, no. 2, pp. E505-E513, 2009.

[69] G. Schoiswohl, M. Schweiger, R. Schreiber et al., "Adipose triglyceride lipase plays a key role in the supply of the working muscle with fatty acids," Journal of Lipid Research, vol. 51, no. 3, pp. 490-499, 2010.

[70] J. Ogasawara, T. Sakurai, T. Kizaki et al., "Higher levels of ATGL are associated with exercise-induced enhancement of lipolysis in rat epididymal adipocytes," PLoS ONE, vol. 7, no. 7, Article ID e40876, 2012.

[71] J. Pagnon, M. Matzaris, R. Stark et al., "Identification and functional characterization of protein kinase A phosphorylation sites in the major lipolytic protein, adipose triglyceride lipase," Endocrinology, vol. 153, no. 9, pp. 4278-4289, 2012.

[72] P. E. Hall, S. R. Smith, D. B. Jack, and M. J. Kendall, "The influence of beta-adrenoceptor blockade on the lipolytic response to exercise," Journal of Clinical Pharmacy and Therapeutics, vol. 12, no. 2, pp. 101-106, 1987.

[73] R. R. Wolfe, S. Klein, F. Carraro, and J.-M. Weber, "Role of triglyceride-fatty acid cycle in controlling fat metabolism in humans during and after exercise," The American Journal of Physiology: Endocrinology and Metabolism, vol. 258, no. 2, part 1, pp. E382-E389, 1990.

[74] S. Klein, E. F. Coyle, and R. R. Wolfe, "Fat metabolism during low-intensity exercise in endurance-trained and untrained men," The American Journal of Physiology-Endocrinology and Metabolism, vol. 267, no. 6, pp. E934-E940, 1994.

[75] Y. Guo, T. C. Walther, M. Rao et al., "Functional genomic screen reveals genes involved in lipid-droplet formation and utilization," Nature, vol. 453, no. 7195, pp. 657-661, 2008. 


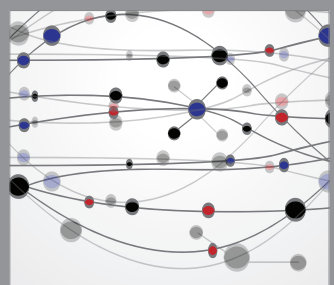

The Scientific World Journal
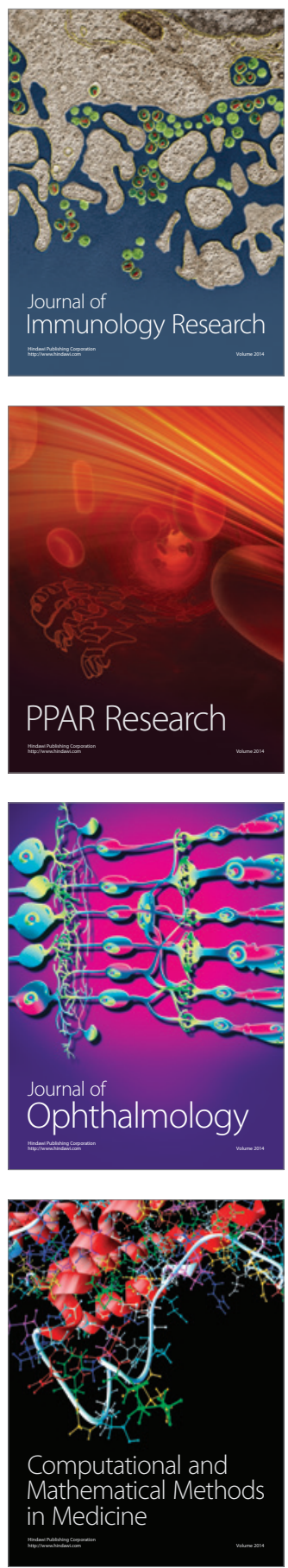

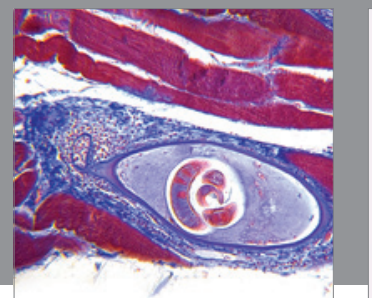

Gastroenterology

Research and Practice
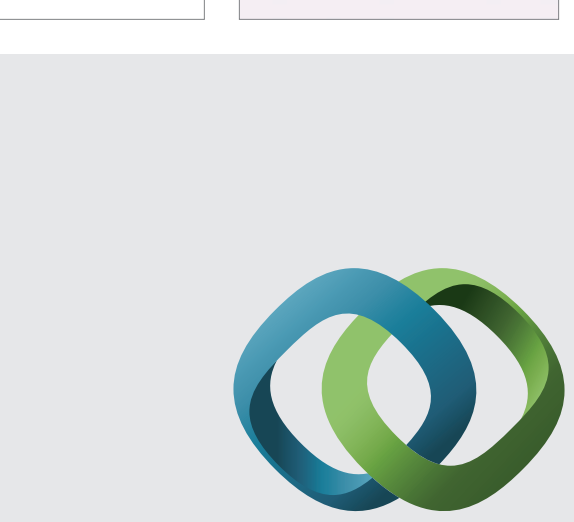

\section{Hindawi}

Submit your manuscripts at

http://www.hindawi.com
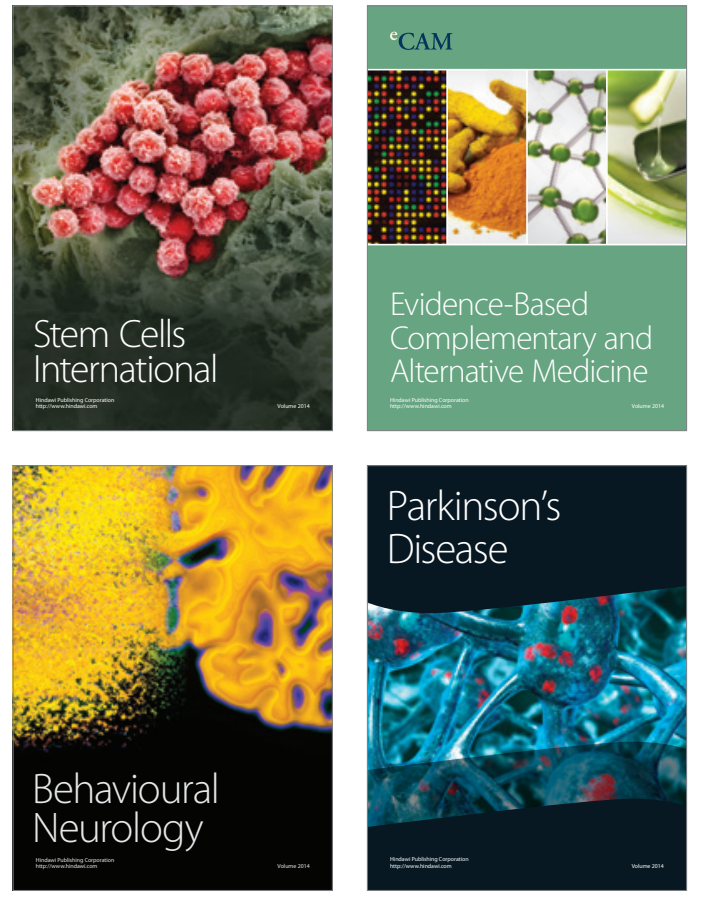
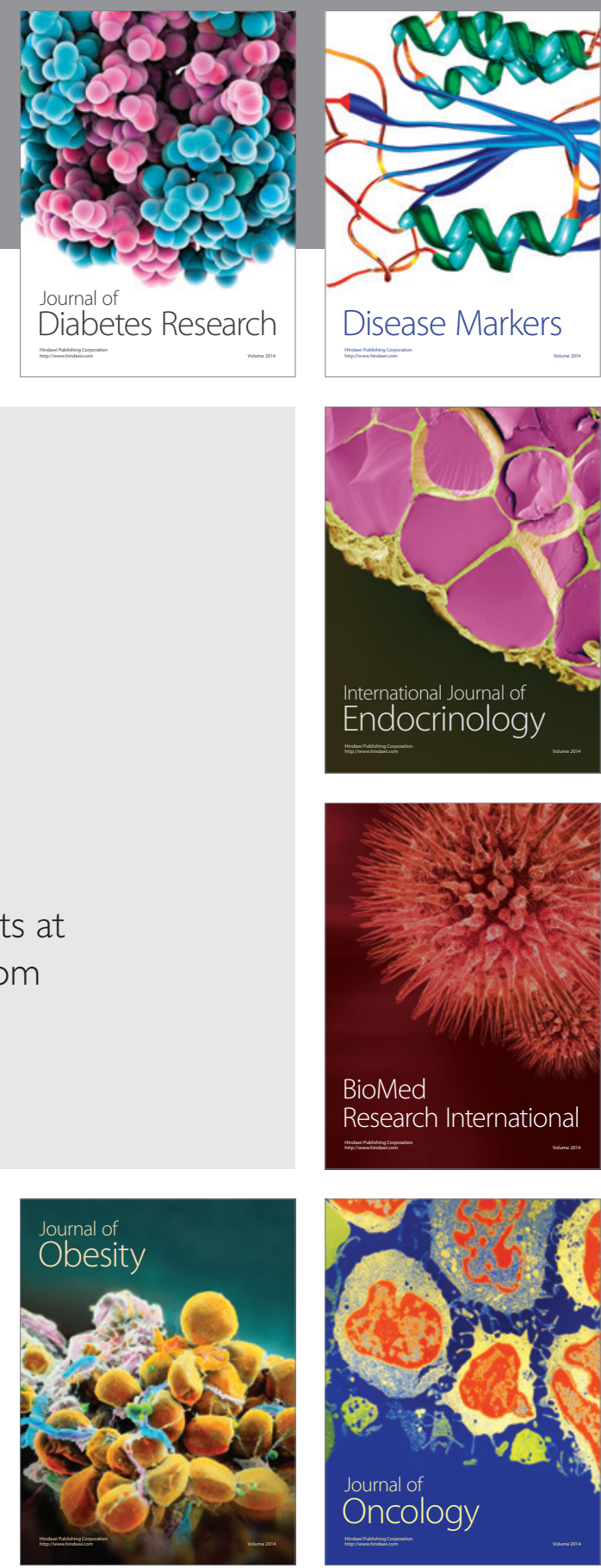

Disease Markers
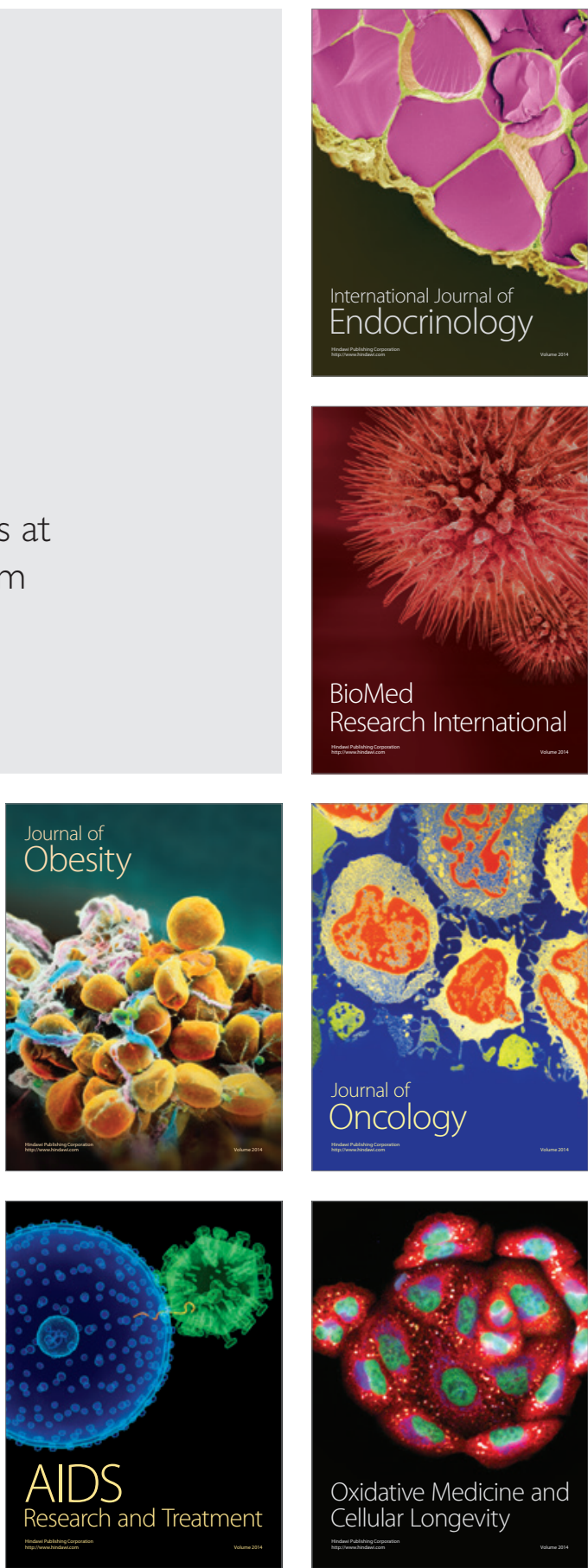